TITLE:

\title{
Human T-cell leukemia virus type 1: replication, proliferation and propagation by Tax and HTLV-1 bZIP factor.
}

$\operatorname{AUTHOR}(\mathrm{S})$ :

Matsuoka, Masao; Yasunaga, Jun-Ichirou

\section{CITATION:}

Matsuoka, Masao ...[et al]. Human T-cell leukemia virus type 1: replication, proliferation and propagation by Tax and HTLV-1 bZIP factor.. Current opinion in virology 2013, 3(6): 684-691

ISSUE DATE:

2013-12

URL:

http://hdl.handle.net/2433/180094

\section{RIGHT:}

(c) 2013 Elsevier B.V.; この論文は出版社版でありません。引用の際には 出版社版をご確認ご利用ください。; This is not the published version. Please cite only the published version. 
Human T-cell leukemia virus type 1: replication, proliferation and propagation by

\section{Tax and HTLV-1 bZIP factor}

Short title: Replication of human T-cell leukemia virus type 1

Masao Matsuoka, and Jun-ichirou Yasunaga

Institute for Virus Research, Kyoto University

53 Shogoin Kawahara-cho, Sakyo-ku, Kyoto 606-8507, Japan

Corresponding author: Masao Matsuoka (mmatsuok@virus.kyoto-u.ac.jp) 


\begin{abstract}
Human T-cell leukemia virus type 1 (HTLV-1) spreads primarily by cell-to-cell transmission. Therefore, HTLV-1 promotes the proliferation of infected cells to facilitate transmission. In HTLV-1 infected individuals, the provirus is present mainly in effector/memory $\mathrm{T}$ cells and Foxp $3+\mathrm{T}$ cells. Recent study suggests that this immunophenotype is acquired by infected cells through the function of HTLV-1 bZIP factor (HBZ). Tax, which is encoded by the plus strand, is critical for viral replication and de novo infection, while HBZ, encoded by the minus strand, is important for proliferation of infected cells. Importantly, HBZ and Tax have opposing functions in most transcription pathways. HBZ and Tax cooperate in elaborate ways to permit viral replication, proliferation of infected cells and propagation of the virus.
\end{abstract}




\section{Introduction}

Transmission of human T-cell leukemia virus type 1 (HTLV-1) is confined to three routes; mother-to-infant, sexual parenteral transmission, and blood transfusion/needle sharing [1]. A striking feature of this virus is that HTLV-1 is transmitted primarily in a cell-to-cell fashion, and infectivity of free virions is very poor. In contrast, another human retrovirus, human immunodeficiency virus (HIV), transmits by both cell-free and cell-to-cell contact. The transmission of HTLV-1 requires living infected cells in breast milk, semen and blood products. To facilitate its transmission, this virus increases the number of infected cells in vivo by stimulating their proliferation.

HTLV-1 was discovered in 1980 as the first human retrovirus [2,3]. Thereafter, this virus was found to be linked with a human disease, adult T-cell leukemia (ATL) [4]. Subsequently it was found that this virus also causes another disease, HTLV-1 associated myelopathy/tropical spastic paraparesis (HAM/TSP), as well as HTLV-1 uveitis, infective dermatitis, and myopathy [1]. These diseases are thought to be associated with the fact that infected host immune cells proliferate in vivo. In this review, we summarize recent findings on the replication of HTLV-1, the proliferation of infected cells, and HTLV-1 propagation -- matters which are closely related for this virus.

\section{Virus entry and cell-to-cell transmission}

Unlike HIV, HTLV-1 can infect a variety of cells; its receptor is thought to be a commonly expressed molecule [5]. It has been reported that HTLV-1 envelope protein 
interacts with three cellular molecules, heparan sulfate proteoglycan (HSPG) [6], neuropilin-1 [7], and a glucose transporter, GLUT1 [8], for entry into cells. Conformational changes of the complex consisting of the HTLV-1 virion and these molecules are thought to occur sequentially during the entry step. First, the HTLV-1 envelope attaches to HSPG, and it then forms complexes with neuropilin-1, which results in stabilization of the complex. Thereafter, GLUT1 is associated with the complex, and finally triggers the fusion process necessary to viral entry [9].

In vitro experiments showed that free virions had poor infectivity, while co-culture of uninfected cells with HTLV-1 infected cells easily established HTLV-1 infected cells [10]. It has been reported that cell-mediated infection of HTLV-1 is 10000 times more efficient than cell-free infection, while cell-to-cell infection by HIV-1 is only twice as efficient as cell-free infection [11]. Two models for the mechanism of cell-to-cell infection by HTLV-1 have been proposed: 1) virological synapse [12] and 2) biofilm [13], and 3) cellular conduits [14]. HTLV-1 infected cells form a virological synapse with uninfected cells; ICAM-1 and LFA-1 are implicated in this synapse formation. Tax is also implicated, specifically in microtubule reorientation [15]. Indeed, Tax enhances cell-to-cell infection [11]. On the other hand, there is evidence to support the biofilm model as well. HTLV-1-infected T cells retain viral particles with virally-induced extracellular matrix components, including collagen, agrin, tetherin and galectin-3 [13]. By cell contact, these viral assemblies adhere to other cells, resulting in infection with HTLV-1.

An increased number of infected cells augments the chances of transmission. Indeed, 
for mother-to-infant transmission, it has been reported that infants have higher chances of getting infected from mothers with higher proviral loads [16].

\section{Transmission of HTLV-1}

HTLV-1 can be transmitted by breast-feeding, sexual contact and blood transfusion. This transmission requires living infected cells, since this virus transmits mainly by cell-to-cell contact (Figure 1). Therefore HTLV-1 infected cells are hypothesized to have attributes that promote their entry into breast milk and semen. It has been reported that breast milk contains T-cells, most of which are effector/memory $\mathrm{T}$ cells expressing LFA1 and ICAM-1 [17], and HTLV-1 provirus has been detected in such effector/memory T cells [18]. These findings suggest that HTLV-1 may confer a phenotype to infected cells that facilitates their entry into breast milk. What component of HTLV-1 confers this effector/memory phenotype to HTLV-1 infected cells? Transgenic expression of HBZ in CD4+ T cells increased the number of effector/memory $\mathrm{T}$ cells and regulatory $\mathrm{T}$ cells, while transgenic mice expressing Tax had no change in the phenotype of CD4+ T cells [19]. This clearly demonstrates that the immunophenotypes of ATL cells and HTLV-1 infected cells are conferred by HBZ, not by Tax. This conferred phenotype, which involves high levels of expression of adhesion molecules, enables HTLV-1 infected cells to enter into breast milk and semen (Figure $1)$.

Next, the virus must override epithelial barriers. How does HTLV-1 cross the 
alimentary tract? Recently, it has been shown that free infectious HTLV-1 virions could cross the epithelial barrier via a transcytosis mechanism [20]. HTLV-1 virions could then infect human dendritic cells (DCs) that exist in the epithelial barrier [21]. Infected DCs likely migrate to draining lymph nodes and then form virological synapses with $\mathrm{T}$ cells (Figure 1). It is difficult to infect $\mathrm{T}$ cells by free virus in vitro. However, free virus can infect DCs, and infected DCs can propagate HTLV-1 infection, suggesting that DCs are the spreader of this virus in vivo [21]. Expression of adhesion and co-stimulatory molecules is critical for immunological synapses between T cells and DCs [22]. Thus, the immunophenotypes (effector/memory T cells, regulatory T cells, and enhanced expression of adhesion molecules) conferred by HBZ are critical for the further spread of this virus in vivo. Thus, using HBZ, HTLV-1 induces infected cells to acquire certain immunophenotypes that facilitate its entry into the body and its subsequent spread within the body.

\section{Clonal proliferation of HTLV-1 infected cells}

After infection, HTLV-1 spreads by cell-to-cell infection and DC mediated infection. This de novo infection of cells is thought to form a pool of infected cells at an early phase of infection. In an experiment using immunodeficient mice with human lymphocytes, administration of reverse transcriptase inhibitors, tenofovir disoproxil fumarate (TDF) or azidothymidine (AZT) beginning after one week of infection could neither block nor decrease proviral load of HTLV-1, while TDF or AZT could block infection when they were injected at the same time of infection [23]. These results 
suggest that a pool of HTLV-1 infected clones is generated at very early phase of infection, and after that time, clonal proliferation of infected cells is predominant. This notion is also supported by clinical findings that reverse transcriptase inhibitors or integrase inhibitors did not alter proviral load in HTLV-1 infected individuals [24,25].

After this early stage of de novo infection, HTLV-1 infected clones are subject to selection by both host immunological attack and viral gene expression. In seroconvertors, the clonality of HTLV-1 infected cells was not stable at an early phase, but then stabilized at the chronic carrier state phase [26], indicating that HTLV-1 infected clones are selected at early phase of infection, and then, selected clones survive in vivo.

Since the HTLV-1 provirus integrates at random sites within the host genome, the clonality of HTLV-1 infected cells can be analyzed by studying these integration sites. Inverse PCR has been used to identify the integration sites and determine the clonality of infected cells $[27,28]$. Recently, high-throughput sequencing has been shown to be capable of detailed analysis of clonality [29]. It is well known that HAM/TSP patients possess higher proviral loads compared with asymptomatic carriers. Analysis of clonality using high-throughput sequencing revealed that the abundance of each clone did not differ, but the number of different clones increased in HAM/TSP patients compared with asymptomatic carriers [29]. In contrast, the abundance of certain clones increased in patients coinfected with HTLV-1 and strongyloides, and in infective dermatitis patients with HTLV-1 infection (IDH patients) [30]. It is noteworthy that ATL develops relatively frequently in IDH patients and HTLV-1 carriers coinfected 
with strongyloides, while the occurrence of ATL is not so frequent in HAM/TSP patients [31]. Thus the enhanced abundance of clones and increased cell division might promote the development of ATL.

What drives cell division of HTLV-1 infected cells? HBZ is ubiquitously expressed in ATL cells and HTLV-1 infected cells in vivo, and promotes their proliferation [32]. In addition, Tax enhances mitogenic antigen-receptor signals $[33,34]$. The details of the mechanisms by which HBZ and Tax stimulate cell proliferation are complex and fascinating. In fact, HBZ and Tax have opposite effects on most signaling pathways [35] (Figure 2). For example, Tax activates the AP-1, NFAT, and CREB pathways while HBZ suppresses them [36,37]. Conversely, Tax inhibits TGF- $\beta /$ Smad pathway whereas HBZ activates it [38]. Tax activates both the canonical and non-canonical NF-kB pathways [39]. HBZ inhibits only the canonical NF-кB pathway by interacting with $\mathrm{p} 65$. Expression of Tax promotes cell proliferation and simultaneously induces cellular senescence by induction of $\mathrm{p} 21$ and $\mathrm{p} 27$. HBZ prevents Tax induced cellular senescence by inhibiting p65 [40]. Thus, the elaborate interactions of various signaling pathways with Tax and HBZ control the proliferation of HTLV-1 infected cells. In addition to this relationship between $\mathrm{HBZ}$ and Tax, it has been reported that HBZ mRNA has growth-promoting activity [32], indicating another complex connection of HBZ as RNA and protein.

Furthermore, we have reported that HBZ suppresses the canonical Wnt pathway by inhibiting DNA binding by TCF-1/LEF-1 transcription factors, while Tax activates canonical Wnt signaling [41]. In contrast, HBZ enhances the transcription of Wnt 5a, 
which is a ligand for the non-canonical Wnt pathway. The canonical Wnt pathway is predominant during the development of $\mathrm{T}$ cells in the thymus, while non-canonical Wnt signaling is activated in peripheral T cells. These findings suggest that HBZ modulates the intra-cellular environment of peripheral T cells, which are natural target of this virus.

\section{Control of transcription of viral genes}

The HTLV-1 provirus encodes the regulatory genes (tax and rex) and the accessory genes $(p 12, p 13, p 30$, and $H B Z)$ in $\mathrm{pX}$ region; these genes regulate viral replication and the proliferation of infected cells [1]. For their transcription, the LTRs at each end of the provirus are used as promoters: the 5'LTR and 3'LTR control the transcription of the viral genes encoded in the plus and minus strands of the provirus, respectively (Figure 3). Since the plus strand of the provirus encodes all structural proteins and the viral genomic RNA, 5'LTR-mediated transcription is required for viral replication and transmission. Tax is a potent activator of viral transcription through the 5'LTR. Tax does not bind to DNA, but activates the transcription of target genes by recruiting various transcription factors and modifying the epigenetic status of promoter regions [42].The association between Tax and CREB is critical for viral gene transcription. There are three 21-bp repeat elements, called Tax-responsive elements (TREs), located in 5'LTR, and the Tax-CREB complex recruits several histone acetyltransferaeses including CREB biding protein (CBP), p300, and p300/CBP-associated factor (PCAF) to the LTR, resulting in induction of viral expression. In addition to Tax, some cellular 
signaling machinery can enhance the activity of the 5'LTR. It has been shown that immune stimulation via T-cell receptor signaling activates the 5'LTR [34,43]. Another study showed that apoptotic signals induced viral transcription [44]. 5'LTR activation by these signals might be advantageous to efficient viral transmission and to viral "escape" from a dying host cell.

Importantly, viral replication is actually suppressed in vivo [45], while viral antigens including Tax are quickly expressed in infected cells after they are transferred to ex vivo culture [46]. Host immune surveillance eliminates infected cells by targeting viral antigens. Among viral proteins, Tax is a major target of cytotoxic T-cells (CTLs) [47]. It is well known that removal of CD8+ T-cells from PBMC allows infected cells to express Tax in the ex vivo cell culture [45], suggesting the presence of immune pressure against Tax in vivo. In addition, it was shown that, even in immunodeficient animal models, viral transcription from 5'LTR was suppressed, indicating that other mechanisms are involved in the silencing [48]. HTLV-1 can suppress its replication by its own proteins; $\mathrm{p} 30$ and HBZ are known to counteract Tax by competing for the binding to CREB, resulting in suppression of HTLV-1 replication [49]. p30 also inhibits the nuclear export of tax/rex mRNA [50]. Epigenetic changes, such as DNA methylation and histone modifications, are also involved in the silencing of HTLV-1. HTLV-1 differs from HIV in this respect. The LTR of HIV contains few CpG sites, while there are DNase hyper-sensitive regions, which explains the resistance of the HIV LTR to silencing $[51,52]$. On the other hand, the HTLV-1 LTR has many CpG sites, suggesting that HTLV-1 is susceptible to gene silencing mediated by DNA methylation. 
CpG methylation in the HTLV-1 provirus is observed in HTLV-1 carriers, and methylation tends to increase and to spread toward the 5'LTR during disease progression [53]. Indeed, Tax expression is frequently missing in ATL cells by epigenetic silencing of the 5'LTR as well as by genetic destruction of the 5'LTR or the tax gene $[54,55]$. Destruction of Tax expression enables ATL cells to escape from Tax-specific CTLs. Recently, it was reported that a histone deacetylase inhibitor, valproate (VPA), enhanced the expression of Tax and Gag in cultured HTLV-1-infected cells from asymptomatic carriers and HAM/TSP patients, suggesting that viral expression is suppressed by epigenetic mechanisms even in the carrier state [56].

The 3'LTR functions as a promoter of the minus strand of the provirus [57]. It has been shown that the 3'LTR is conserved in all cases and CpGs are hypomethylated, suggesting that transcription through the 3'LTR is required for infected cells $[53,58]$. The $H B Z$ gene is encoded in the minus strand, and alternative splicing makes the splice variants, the spliced and unspliced isoforms $[59,60]$. The spliced $H B Z$ gene is transcribed from the 3'LTR, and the SP1 binding elements in 3'LTR are important for its transcription [57]. SP1 is a transcription factor ubiquitously expressed in a variety of cells, a fact which corresponds to the finding that HBZ is constitutively expressed in all ATL cases and HTLV-1 infected individuals [61]. It was also reported that SP1 forms a complex with HBZ and JunD and enhances the promoter activity of HBZ [62], suggesting that SP1 is a key transcription factor for the activity of the 3'LTR. Interestingly, it was shown that Tax positively regulates 3'LTR activity [57], although the significance of this observation remains unclear. Further studies need to be 
conducted for us to fully understand the regulation of transcription via the 3'LTR.

\section{The host immune system and proliferation of infected cells}

After infection, provirus load (the number of infected cells) and clonality are determined by the balance between viral gene expression and the host immune response [63]. As described, Tax is highly immunogenic, while the immunogenicity of HBZ protein is very low [64]. However, provirus load is well correlated with the immune response to HBZ; a low immune response to $\mathrm{HBZ}$ is associated with a high provirus load in HTLV-1 infected individuals. It is thought that HTLV-1 evolves to reduce the immunogenicity of HBZ, which is constitutively expressed and critical for the proliferation of infected cells. Conversely, HTLV-1 infected cells express Tax more transiently. Tax is important for viral replication and de novo infection by HTLV-1. However, due to the high immunogenicity of Tax, HTLV-1 suppresses Tax expression in vivo by elaborately regulated mechanisms.

\section{Conclusion}

HTLV-1 evolved to propagate by cell-to-cell transmission. Therefore, this virus induces the proliferation of infected cells while under the pressure of host immune system. To this end, Tax and HBZ cooperate with each other in complicated ways to permit viral replication and promote the proliferation of infected cells. These phenomena are closely associated with the pathogenesis of this virus. 


\section{Acknowledgements}

We thank Linda Kingsbury for proof-reading of this manuscript. This study was supported by a grant from SENSHIN medical research foundation to MM, a Grant-in-aid for Scientific Research from the Ministry of Education, Science, Sports, and Culture of Japan (22114003) to MM, and a grant from the Takeda Science Foundation to JY.

\section{References}

1. Matsuoka M, Jeang KT: Human T-cell leukaemia virus type 1 (HTLV-1) infectivity and cellular transformation. Nat Rev Cancer 2007, 7:270-280.

2. Poiesz BJ, Ruscetti FW, Gazdar AF, Bunn PA, Minna JD, Gallo RC: Detection and isolation of type $\mathbf{C}$ retrovirus particles from fresh and cultured lymphocytes of a patient with cutaneous T-cell lymphoma. Proc Natl Acad Sci U S A 1980, 77:7415-7419.

3. Gallo RC: The discovery of the first human retrovirus: HTLV-1 and HTLV-2. Retrovirology 2005, 2:17.

4. Takatsuki K: Discovery of adult T-cell leukemia. Retrovirology 2005, 2:16.

5. Koyanagi Y, Itoyama Y, Nakamura N, Takamatsu K, Kira J, Iwamasa T, Goto I, Yamamoto N: In vivo infection of human T-cell leukemia virus type I in non-T cells. Virology 1993, 196:25-33.

6. Jones KS, Petrow-Sadowski C, Bertolette DC, Huang Y, Ruscetti FW: Heparan sulfate proteoglycans mediate attachment and entry of human T-cell leukemia virus type 1 virions into CD4+ T cells. $J$ Virol 2005, 79:12692-12702.

7. Ghez D, Lepelletier Y, Lambert S, Fourneau JM, Blot V, Janvier S, Arnulf B, van Endert PM, Heveker N, Pique C, et al.: Neuropilin-1 is involved in human T-cell lymphotropic virus type 1 entry. $J$ Virol 2006, 80:6844-6854. 
8. Manel N, Kim FJ, Kinet S, Taylor N, Sitbon M, Battini JL: The ubiquitous glucose transporter GLUT-1 is a receptor for HTLV. Cell 2003, 115:449-459.

9. Jones KS, Lambert S, Bouttier M, Benit L, Ruscetti FW, Hermine O, Pique C:

Molecular aspects of HTLV-1 entry: functional domains of the HTLV-1 surface subunit (SU) and their relationships to the entry receptors. Viruses 2011, 3:794-810.

*This review summarizes the previously reports on the functional domains of HTLV-1 envelope, and proposes a multi-receptor model for HTLV-1 entry.

10. Derse D, Hill SA, Lloyd PA, Chung H, Morse BA: Examining human T-lymphotropic virus type 1 infection and replication by cell-free infection with recombinant virus vectors. J Virol 2001, 75:8461-8468.

11. Mazurov D, Ilinskaya A, Heidecker G, Lloyd P, Derse D: Quantitative comparison of HTLV-1 and HIV-1 cell-to-cell infection with new replication dependent vectors. PLoS Pathog 2010, 6:e1000788.

12. Igakura T, Stinchcombe JC, Goon PK, Taylor GP, Weber JN, Griffiths GM, Tanaka Y, Osame M, Bangham CR: Spread of HTLV-I between lymphocytes by virus-induced polarization of the cytoskeleton. Science 2003, 299:1713-1716.

13. Pais-Correia AM, Sachse M, Guadagnini S, Robbiati V, Lasserre R, Gessain A, Gout O, Alcover A, Thoulouze MI: Biofilm-like extracellular viral assemblies mediate HTLV-1 cell-to-cell transmission at virological synapses. Nat Med 2010, 16:83-89.

** This publication shows that HTLV-1-infected cells capture viral particles via extracelluar assemblies, and facilitate viral transfer to uninfected cells through this "biofilm-like" matrix components. The extracellular components include collagen, agrin, and cellular linker proteins such as tetherin and galectin-3.

14. Van Prooyen N, Gold H, Andresen V, Schwartz O, Jones K, Ruscetti F, Lockett S, Gudla P, Venzon D, Franchini G: Human T-cell leukemia virus type 1 p8 protein increases cellular conduits and virus transmission. Proc Natl Acad Sci U S A 2010, 107:20738-20743.

15. Nejmeddine M, Barnard AL, Tanaka Y, Taylor GP, Bangham CR: Human T-lymphotropic virus, type 1 , tax protein triggers microtubule reorientation in the virological synapse. J Biol Chem 2005, 280:29653-29660.

16. Hisada M, Maloney EM, Sawada T, Miley WJ, Palmer P, Hanchard B, Goedert JJ, 
Manns A: Virus markers associated with vertical transmission of human $T$ lymphotropic virus type 1 in Jamaica. Clin Infect Dis 2002, 34:1551-1557.

17. Bertotto A, Gerli R, Fabietti G, Crupi S, Arcangeli C, Scalise F, Vaccaro R: Human breast milk $\mathrm{T}$ lymphocytes display the phenotype and functional characteristics of memory T cells. Eur J Immunol 1990, 20:1877-1880.

18. Yasunaga J, Sakai T, Nosaka K, Etoh K, Tamiya S, Koga S, Mita S, Uchino M, Mitsuya H, Matsuoka M: Impaired production of naive T lymphocytes in human T-cell leukemia virus type I-infected individuals: its implications in the immunodeficient state. Blood 2001, 97:3177-3183.

19. Satou Y, Yasunaga J, Zhao T, Yoshida M, Miyazato P, Takai K, Shimizu K, Ohshima K, Green PL, Ohkura N, et al.: HTLV-1 bZIP Factor Induces T-Cell Lymphoma and Systemic Inflammation In Vivo. PLoS Pathog 2011, 7:e1001274.

** This publication shows that HBZ transgenic mice develop systemic inflammation and T-cell lymphomas. In this transgenic mouse, the number of effector/memory T-cells and regulatory T-cells are increased. These finding suggest that HBZ modulates cellular immune system and induces those fatal diseases.

20. Martin-Latil S, Gnadig NF, Mallet A, Desdouits M, Guivel-Benhassine F, Jeannin P, Prevost MC, Schwartz O, Gessain A, Ozden S, et al.: Transcytosis of HTLV-1 across a tight human epithelial barrier and infection of subepithelial dendritic cells. Blood 2012, 120:572-580.

* This study first shows that transcytosis of virus is the possible mechanism for virus to pass through alimentary tract.

21. Jones KS, Petrow-Sadowski C, Huang YK, Bertolette DC, Ruscetti FW: Cell-free HTLV-1 infects dendritic cells leading to transmission and transformation of CD4(+) T cells. Nat Med 2008, 14:429-436.

22. Huppa JB, Davis MM: T-cell-antigen recognition and the immunological synapse. Nat Rev Immunol 2003, 3:973-983.

23. Miyazato P, Yasunaga J, Taniguchi Y, Koyanagi Y, Mitsuya H, Matsuoka M: De novo human T-cell leukemia virus type 1 infection of human lymphocytes in NOD-SCID, common gamma-chain knockout mice. J Virol 2006, 80:10683-10691.

24. Taylor GP, Goon P, Furukawa Y, Green H, Barfield A, Mosley A, Nose H, Babiker 
A, Rudge $\mathrm{P}$, Usuku K, et al.: Zidovudine plus lamivudine in Human

T-Lymphotropic Virus type-I-associated myelopathy: a randomised trial. Retrovirology 2006, 3:63.

25. Trevino A, Parra P, Bar-Magen T, Garrido C, de Mendoza C, Soriano V: Antiviral effect of raltegravir on HTLV-1 carriers. J Antimicrob Chemother 2012, 67:218-221.

26. Okayama A, Stuver S, Matsuoka M, Ishizaki J, Tanaka G, Kubuki Y, Mueller N, Hsieh CC, Tachibana N, Tsubouchi H: Role of HTLV-1 proviral DNA load and clonality in the development of adult $T$-cell leukemia/lymphoma in asymptomatic carriers. Int J Cancer 2004, 110:621-625.

27. Etoh K, Tamiya S, Yamaguchi K, Okayama A, Tsubouchi H, Ideta T, Mueller N, Takatsuki K, Matsuoka M: Persistent clonal proliferation of human T-lymphotropic virus type I-infected cells in vivo. Cancer Res 1997, 57:4862-4867.

28. Wattel E, Vartanian JP, Pannetier C, Wain-Hobson S: Clonal expansion of human T-cell leukemia virus type I-infected cells in asymptomatic and symptomatic carriers without malignancy. $J$ Virol 1995, 69:2863-2868.

29. Gillet NA, Malani N, Melamed A, Gormley N, Carter R, Bentley D, Berry C, Bushman FD, Taylor GP, Bangham CR: The host genomic environment of the provirus determines the abundance of HTLV-1-infected $\mathbf{T}$ cell clones. Blood 2011

** This study analyzed HTLV-1 proviral integration sites using the deep sequencing. It is shown that HTLV-1 is frequently integrated in transcriptionally silenced regions in asymptomatic carriers, suggesting negative selection by immune pressure. The abundance of HTLV-1 clones is influenced by genomic features of the host DNA flanking the provirus.

30. Gillet NA, Cook L, Laydon DJ, Hlela C, Verdonck K, Alvarez C, Gotuzzo E, Clark D, Farre L, Bittencourt A, et al.: Strongyloidiasis and Infective Dermatitis Alter Human T Lymphotropic Virus-1 Clonality in vivo. PLoS Pathog 2013, 9:e1003263.

*This publication shows that strongyloidiasis and infective dermatitis in HTLV-1 carriers increase the risk of development of HTLV-1-associated diseases by increasing 
the abundance of HTLV-1-infected clones and new infections in vivo.

31. Nakada K, Yamaguchi K, Furugen S, Nakasone T, Nakasone K, Oshiro Y, Kohakura M, Hinuma Y, Seiki M, Yoshida M, et al.: Monoclonal integration of HTLV-I proviral DNA in patients with strongyloidiasis. Int J Cancer 1987, 40:145-148.

32. Satou Y, Yasunaga J, Yoshida M, Matsuoka M: HTLV-I basic leucine zipper factor gene mRNA supports proliferation of adult $\mathbf{T}$ cell leukemia cells. Proc Natl Acad Sci U S A 2006, 103:720-725.

33. Maruyama M, Shibuya H, Harada H, Hatakeyama M, Seiki M, Fujita T, Inoue J, Yoshida M, Taniguchi T: Evidence for aberrant activation of the interleukin-2 autocrine loop by HTLV-1-encoded p40x and T3/Ti complex triggering. Cell 1987, 48:343-350.

34. Swaims AY, Khani F, Zhang Y, Roberts AI, Devadas S, Shi Y, Rabson AB: Immune activation induces immortalization of HTLV-1 LTR-Tax transgenic CD4+ T cells. Blood 2010, 116:2994-3003.

35. Matsuoka M, Jeang KT: Human T-cell leukemia virus type 1 (HTLV-1) and leukemic transformation: viral infectivity, Tax, HBZ and therapy. Oncogene 2011, 30:1379-1389.

36. Sugata K, Satou Y, Yasunaga J, Hara H, Ohshima K, Utsunomiya A, Mitsuyama M, Matsuoka M: HTLV-1 bZIP factor impairs cell-mediated immunity by suppressing production of Th1 cytokines. Blood 2012, 119:434-444.

37. Grassmann R, Aboud M, Jeang KT: Molecular mechanisms of cellular transformation by HTLV-1 Tax. Oncogene 2005, 24:5976-5985.

38. Zhao T, Satou Y, Sugata K, Miyazato P, Green PL, Imamura T, Matsuoka M: HTLV-1 bZIP factor enhances TGF-\{beta\} signaling through p300 coactivator. Blood 2011, 118:1865-1876.

39. Sun SC, Yamaoka S: Activation of NF-kappaB by HTLV-I and implications for cell transformation. Oncogene 2005, 24:5952-5964.

40. Zhi H, Yang L, Kuo YL, Ho YK, Shih HM, Giam CZ: NF-kappaB hyper-activation by HTLV-1 tax induces cellular senescence, but can be alleviated by the viral anti-sense protein HBZ. PLoS pathogens 2011, 7:e1002025.

41. Ma G, Yasunaga J, Fan J, Yanagawa S, Matsuoka M: HTLV-1 bZIP factor 
dysregulates the Wnt pathways to support proliferation and migration of adult T-cell leukemia cells. Oncogene 2012.

42. Kashanchi F, Brady JN: Transcriptional and post-transcriptional gene regulation of HTLV-1. Oncogene 2005, 24:5938-5951.

43. Lin HC, Hickey M, Hsu L, Medina D, Rabson AB: Activation of human T cell leukemia virus type 1 LTR promoter and cellular promoter elements by $T$ cell receptor signaling and HTLV-1 Tax expression. Virology 2005, 339:1-11.

44. Abou-Kandil A, Chamias R, Huleihel M, Godbey WT, Aboud M: Role of caspase 9 in activation of HTLV-1 LTR expression by DNA damaging agents. Cell Cycle 2011, 10:3337-3345.

45. Hanon E, Hall S, Taylor GP, Saito M, Davis R, Tanaka Y, Usuku K, Osame M, Weber JN, Bangham CR: Abundant tax protein expression in CD4+ T cells infected with human T-cell lymphotropic virus type I (HTLV-I) is prevented by cytotoxic T lymphocytes. Blood 2000, 95:1386-1392.

46. Umadome H, Uchiyama T, Hori T, Tamori S, Motoi T, Araki K, Uchino H: Close association between interleukin 2 receptor mRNA expression and human $T$ cell leukemia/lymphoma virus type I viral RNA expression in short-term cultured leukemic cells from adult $\mathbf{T}$ cell leukemia patients. $J$ Clin Invest 1988, 81:52-61.

47. Kannagi M, Harada S, Maruyama I, Inoko H, Igarashi H, Kuwashima G, Sato S, Morita M, Kidokoro M, Sugimoto M, et al.: Predominant recognition of human T cell leukemia virus type I (HTLV-I) pX gene products by human CD8+ cytotoxic $\mathbf{T}$ cells directed against HTLV- I-infected cells. Int Immunol 1991, 3:761-767.

48. Furuta RA, Sugiura K, Kawakita S, Inada T, Ikehara S, Matsuda T, Fujisawa J:

Mouse model for the equilibration interaction between the host immune system and human T-cell leukemia virus type 1 gene expression. J Virol 2002, 76:2703-2713.

49. Yasunaga J, Matsuoka M: Leukaemogenic mechanism of human T-cell

leukaemia virus type I. Rev Med Virol 2007, 17:301-311.

50. Nicot C, Dundr M, Johnson JM, Fullen JR, Alonzo N, Fukumoto R, Princler GL, Derse D, Misteli T, Franchini G: HTLV-1-encoded p30(II) is a 
post-transcriptional negative regulator of viral replication. Nat Med 2004, 10:197-201.

51. Pion M, Jordan A, Biancotto A, Dequiedt F, Gondois-Rey F, Rondeau S, Vigne R, Hejnar J, Verdin E, Hirsch I: Transcriptional suppression of in vitro-integrated human immunodeficiency virus type 1 does not correlate with proviral DNA methylation. J Virol 2003, 77:4025-4032.

52. Verdin E: DNase I-hypersensitive sites are associated with both long terminal repeats and with the intragenic enhancer of integrated human immunodeficiency virus type 1. J Virol 1991, 65:6790-6799.

53. Taniguchi Y, Nosaka K, Yasunaga J, Maeda M, Mueller N, Okayama A, Matsuoka M: Silencing of human T-cell leukemia virus type I gene transcription by epigenetic mechanisms. Retrovirology 2005, 2:64.

54. Fan J, Ma G, Nosaka K, Tanabe J, Satou Y, Koito A, Wain-Hobson S, Vartanian JP, Matsuoka M: APOBEC3G generates nonsense mutations in human T-cell leukemia virus type 1 proviral genomes in vivo. J Virol 2010, 84:7278-7287.

55. Takeda S, Maeda M, Morikawa S, Taniguchi Y, Yasunaga J, Nosaka K, Tanaka Y, Matsuoka M: Genetic and epigenetic inactivation of tax gene in adult T-cell leukemia cells. Int J Cancer 2004, 109:559-567.

56. Belrose G, Gross A, Olindo S, Lezin A, Dueymes M, Komla-Soukha I, Smadja D, Tanaka Y, Willems L, Mesnard JM, et al.: Effects of valproate on Tax and HBZ expression in HTLV-1 and HAM/TSP T lymphocytes. Blood 2011, 118:2483-2491.

*This publication shows that a histone deacetylation inhibitor, valproate (VPA), enhances expression of Tax and Gag in cultured cells from HTLV-1-infected individuals. In contrast, HBZ expresssion is suppressed by VPA, suggesting that histone deacetylase(s) is involved in viral replication and cellular proliferation. VPA also induces apoptosis in HTLV-1-infected cells.

57. Yoshida M, Satou Y, Yasunaga J, Fujisawa J, Matsuoka M: Transcriptional control of spliced and unspliced human T-cell leukemia virus type 1 bZIP factor (HBZ) gene. J Virol 2008, 82:9359-9368.

58. Miyazaki M, Yasunaga J, Taniguchi Y, Tamiya S, Nakahata T, Matsuoka M: Preferential selection of human T-cell leukemia virus type 1 provirus lacking the $5^{\prime}$ long terminal repeat during oncogenesis. J Virol 2007, 
81:5714-5723.

59. Gaudray G, Gachon F, Basbous J, Biard-Piechaczyk M, Devaux C, Mesnard JM:

The complementary strand of the human T-cell leukemia virus type 1 RNA genome encodes a bZIP transcription factor that down-regulates viral transcription. J Virol 2002, 76:12813-12822.

60. Yasunaga J, Matsuoka M: Molecular mechanisms of HTLV-1 infection and pathogenesis. Int $J$ Hematol 2011, 94:435-442.

61. Saito M, Matsuzaki T, Satou Y, Yasunaga J, Saito K, Arimura K, Matsuoka M, Ohara Y: In vivo expression of the HBZ gene of HTLV-1 correlates with proviral load, inflammatory markers and disease severity in HTLV-1 associated myelopathy/tropical spastic paraparesis (HAM/TSP). Retrovirology 2009, 6:19.

62. Gazon H, Lemasson I, Polakowski N, Cesaire R, Matsuoka M, Barbeau B, Mesnard JM, Peloponese JM, Jr.: Human T-cell leukemia virus type 1 (HTLV-1) bZIP factor requires cellular transcription factor JunD to upregulate HTLV-1 antisense transcription from the 3 ' long terminal repeat. $J$ Virol 2012 , 86:9070-9078.

63. Bangham CR, Meekings K, Toulza F, Nejmeddine M, Majorovits E, Asquith B, Taylor GP: The immune control of HTLV-1 infection: selection forces and dynamics. Front Biosci 2009, 14:2889-2903.

64. Macnamara A, Rowan A, Hilburn S, Kadolsky U, Fujiwara H, Suemori K, Yasukawa M, Taylor G, Bangham CR, Asquith B: HLA class I binding of HBZ determines outcome in HTLV-1 infection. PLoS Pathog 2010, 6.

** This publication first reported the presence of cytotoxic T lymphocytes to HBZ, and suggests the importance of immune response against HBZ to pathogenesis of HTLV-1. 


\section{Figure legends}

Figure 1. Transmission and de novo infection with HTLV-1

HTLV-1 is transmitted via breast feeding, sexual intercourse, and blood transfusion. For any of these routes, living infected cells are essential. HTLV-1 infected cells have the immunophenotypes of effector/memory $\mathrm{T}$ cells or regulatory $\mathrm{T}$ cells. These cells tend to enter breast milk. HTLV-1 enters into the alimentary tract by transcytosis, and infects dendritic cells. Infected DCs transmit virus to uninfected $\mathrm{T}$ cells via virological synapses. Then infected T cells expand clonally in vivo.

Figure 2. Opposite functions of Tax and HBZ

Tax and HBZ have opposite functions in many signaling pathways. Tax activates the CREB pathway by recruiting CREB and $\mathrm{CBP} / \mathrm{p} 300$ to the promoters of target genes, whereas HBZ also interacts with the same proteins, suppressing Tax-mediated transcription. Tax activates both the classical and the alternative NF- $\mathrm{KB}$ pathways, and HBZ selectively suppresses classical signaling by targeting p65. Tax activates PI3K and induces the transcription of AP-1 target genes. HBZ negatively regulates this pathway by its inhibitory interactions with c-Jun and JunB through their bZIP domains. Tax forms a complex with DAPLE and DVL, and activates the canonical Wnt pathway. HBZ interacts with LEF-1/TCF-1 at point further downstream in this pathway and suppresses the transcription of the target genes. Tax has a negative effect on the TGF- $\beta$ /SMAD pathway; however, HBZ activates it by interacting with SMAD2/3 and 
recruiting $\mathrm{CBP} / \mathrm{p} 300$ to the promoters of the target genes.

Figure 3. Transcriptional control of HTLV-1 provirus

The 5'LTR is a promoter and enhancer of the plus strand transcripts that encode the viral genomic RNA, the structural proteins (Gag, Pol, and Env), and the regulatory/accessory proteins (Tax, Rex, p12, p13, and p30). Transcription via the 5'LTR is induced by recruiting the Tax-CREB-CBP/p300 complex to TREs in U3 region of 5'LTR, whereas the other viral factors (HBZ and p30) and epigenetic modifications on the 5'LTR suppress it. Some extrinsic factors are also associated with the activity of 5'LTR. In contrast, the 3'LTR is constitutively activated, and recruitment of SP-1 to its binding elements in U5 of the 3'LTR is important for 3'LTR activity. HBZ is encoded in the minus strand, and the HBZ-JunD complex enhances the transcriptional function of SP-1 on the 3'LTR. 


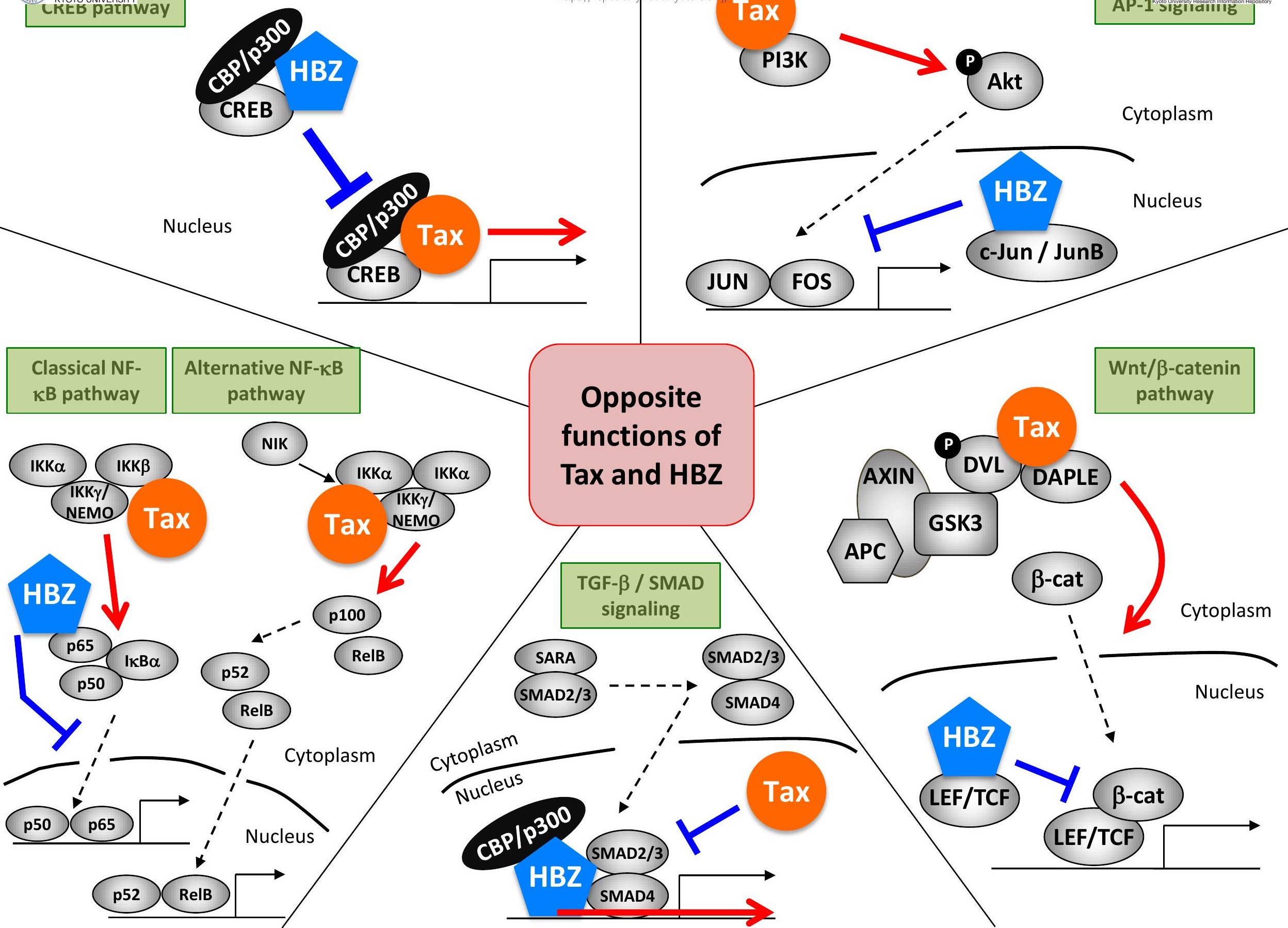



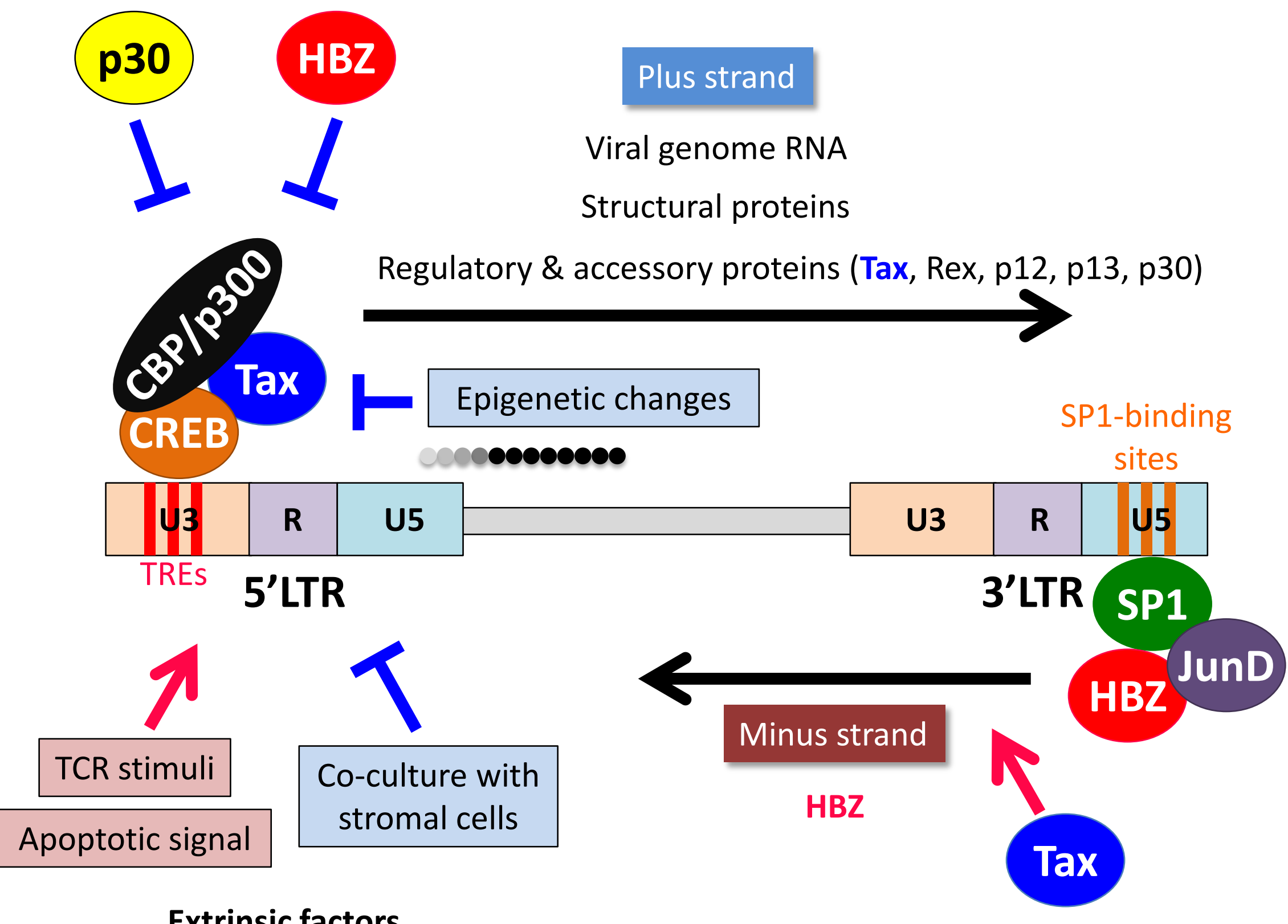

Extrinsic factors 